\title{
Reactivation of cocaine reward memory engages the Akt/GSK3/mTOR signaling pathway and can be disrupted by GSK3 inhibition
}

\author{
Xiangdang Shi • Jonathan S. Miller • Lauren J. Harper • \\ Rachel L. Poole • Thomas J. Gould • Ellen M. Unterwald
}

Received: 26 September 2013 / Accepted: 4 February 2014 / Published online: 5 March 2014

(C) The Author(s) 2014. This article is published with open access at Springerlink.com

\begin{abstract}
Rational Memories return to a labile state following their retrieval and must undergo a process of reconsolidation to be maintained. Thus, disruption of cocaine reward memories by interference with reconsolidation may be therapeutically beneficial in the treatment of cocaine addiction.

Objective The objectives were to elucidate the signaling pathway involved in reconsolidation of cocaine reward memory and to test whether targeting this pathway could disrupt cocaine-associated contextual memory.

Methods Using a mouse model of conditioned place preference, regulation of the activity of glycogen synthase kinase-3 (GSK3), mammalian target of Rapamycin complex 1 (mTORC1), P70S6K, $\beta$-catenin, and the upstream signaling molecule Akt, was studied in cortico-limbic-striatal circuitry after re-exposure to an environment previously paired with cocaine.

Result Levels of phosporylated Akt-Thr308, GSK $3 \alpha$-Ser21, GSK3 $\beta$-Ser9, mTORC1, and P70S6K were reduced in the nucleus accumbens and hippocampus $10 \mathrm{~min}$ after the reactivation of cocaine cue memories. Levels of pAkt and pGSK3 were also reduced in the prefrontal cortex. Since reduced phosphorylation of GSK3 indicates heightened enzyme activity, the effect of a selective GSK3 inhibitor, SB216763, on reconsolidation was tested. Administration of SB216763 immediately after exposure to an environment previously paired with cocaine abrogated a previously established place
\end{abstract}

X. Shi $\cdot$ J. S. Miller $\cdot$ L. J. Harper · E. M. Unterwald $(\bowtie)$

Department of Pharmacology and the Center for Substance Abuse Research, Temple University School of Medicine, Philadelphia, PA 19140, USA

e-mail: ellen.unterwald@temple.edu

R. L. Poole · T. J. Gould

Department of Psychology, Temple University, Philadelphia, PA, USA preference, suggesting that GSK3 inhibition interfered with reconsolidation of cocaine-associated reward memories. Conclusions These findings suggest that the Akt/GSK3/ mTORC1 signaling pathway in the nucleus accumbens, hippocampus, and/or prefrontal cortex is critically involved in the reconsolidation of cocaine contextual reward memory. Inhibition of GSK3 activity during memory retrieval can erase an established cocaine place preference.

Keywords Cocaine Conditioned place preference . Glycogen synthase kinase-3 $\cdot$ Memory $\cdot$ Reconsolidation · mTORC1 $\cdot$ Mouse $\cdot$ Reward $\cdot$ Akt $\cdot$ Protein kinase B $\cdot$ Nucleus accumbens $\cdot$ Hippocampus $\cdot$ Fear conditioning

\section{Introduction}

Compulsive drug use is the hallmark of addiction, and conditioned learning plays a large role in the development of this habitual behavior (Berke and Hyman 2000). Addictive drugs such as cocaine engage molecular signaling pathways that are normally involved in associative learning processes. Exposure to cues previously associated with cocaine availability can lead to a conditioned physiological response accompanied by intense drug craving (Ehrman et al. 1992). Memories for cocaine-associated cues are highly resistant to extinction (Miller and Marshall 2005). Conditioned responses to these cues persist during drug abstinence and contribute to the high rates of relapse to cocaine use even after prolonged periods of abstinence. Thus, a goal of addiction treatment is to extinguish previously learned associations between the positive subjective effects of cocaine and environmental cues signaling cocaine availability.

Memories undergo a reconsolidation process after reactivation and retrieval. Following the reactivation of cocaineassociated memories, exposure to the previous conditioned stimulus (i.e., cue) in the absence of the unconditioned 
stimulus (i.e., cocaine) reactivates previously learned memories resulting in reconsolidation or strengthening of the memory (Mactutus et al. 1979; Przybyslawski and Sara 1997). During the reactivation process, memory traces are labile and can be manipulated behaviorally or pharmacologically (Nader et al. 2000). As drug-associated cues can trigger relapse to drug-seeking behaviors, pharmacological inhibition of memory reconsolidation processes that maintain intrusive cocaine-related memories may be a useful approach to prevent relapse. Although the neural circuitry of associative learning and cue-induced drug seeking has been investigated, the molecular signaling pathways engaged in this process have not been well-described. As such, the goal of the present study was to investigate the key intracellular signaling proteins involved in the reconsolidation of cocaine-associated memories and to test whether interfering with the signal transduction of these proteins can abolish cocaine-cue memories.

The glycogen synthase kinase 3 (GSK3) pathway has received attention for its role in a variety of neuropsychiatric conditions (Jope and Roh 2006). Two GSK3 isoforms exist in brain, GSK $3 \alpha$ and GSK $3 \beta$. GSK 3 is a constitutively active kinase, and its activity is inhibited by phosphorylation of the N-terminal serine- 21 of GSK $3 \alpha$ and serine-9 of GSK3 $\beta$ (Leroy and Brion 1999; Woodgett 1990). Many substrates of GSK3 are under negative regulation which is released when GSK3 is phosphorylated. GSK3 phosphorylation and hence activity is controlled by several kinases including Akt, also known as protein kinase $\mathrm{B}$, which is a serine/threonine kinase downstream of phosphoinositide 3-kinase (PI3K) (Cross et al. 1995). Although both isoforms of GSK-3 are implicated in neurological and psychiatric disorders, most investigations have focused on the $\beta$ isoform which is widely expressed throughout the brain. GSK3 has been shown to be a critical molecular substrate involved in psychostimulant-induced behaviors. In our previous studies, inhibition of GSK3 attenuated hyper-locomotion produced by acute administration of cocaine or amphetamine and prevented the development of locomotor sensitization following their repeated administration (Enman and Unterwald 2012; Miller et al. 2009). Likewise, inhibitors of GSK3 reduce methamphetamine-induced locomotor sensitization (Xu et al. 2011). Recent work has shown that administration of a GSK3 inhibitor into the basolateral amygdala immediately after exposure to a cocaine-paired environment disrupts the reconsolidation of cocaine cue memory (Wu et al. 2011). Although the importance of GSK3 has been noted, the signaling pathway involved in the reconsolidation of cocaine-related memories beyond GSK3 has not been investigated.

GSK3 $\beta$ is important for the regulation of an assembly of transcription factors including $\beta$-catenin, which is an important component of the Wnt signal transduction pathway (for review, see MacDonald et al. (2009)). GSK3, as an integrator of Akt and Wnt signals, also plays a central role in the regulation of mammalian target of rapamycin (mTOR) during synaptic plasticity (Ma et al. 2011). mTOR is a serine/ threonine protein kinase that regulates cell growth and survival by controlling translation in response to nutrients and growth factors (Gingras et al. 2001; Proud 2007). mTOR is a downstream effector of the PI3K/Akt pathway and forms two distinct multiprotein complexes, mTORC1 and mTORC2 (Loewith et al. 2002). mTORC1 includes regulatoryassociated protein of mTOR (Raptor) and proline-rich Akt substrate $40 \mathrm{kDa}$ (PRAS40) and promotes protein synthesis and cell growth through phosphorylation of two main substrates, eukaryotic initiation factor 4E-binding protein 1 (4EBP1) and p70 ribosomal S6 kinase 1 (P70S6K). mTORC1 signaling is necessary for memory formation and storage (Parsons et al. 2006; Stoica et al. 2011). In addition, administration of the mTOR inhibitor rapamycin can block the expression of cocaine-induced place preference and locomotor sensitization (Bailey et al. 2011).

In the present study, GSK3 and its major upstream (Akt) and downstream signaling molecules ( $\beta$-catenin and mTORC1) were measured in the prefrontal cortex, nucleus accumbens, caudate putamen, and hippocampus, in order to determine whether the Akt/GSK3/mTOR and/or Wnt/GSK3/ $/$-catenin signaling pathways are involved in cocaine-associated memory reconsolidation. The importance of GSK3 activity for the maintenance of cocaine-paired cue memories and contextual fear conditioning was also elucidated.

\section{Materials and methods}

\section{Animals}

Male CD-1 mice ( 8 weeks old) were obtained from Charles River Laboratories (Wilmington, MA). Mice were housed four or five per Plexiglas cage $(28 \times 18 \times 14 \mathrm{~cm})$ without additional enrichment objects in a temperature and relative humidity-controlled room with a 12-h light/dark cycle (lights on at 7:00 AM). All animals had access to standard laboratory chow and tap water ad libitum. Animals were housed for 5 days prior to behavioral testing and were handled and weighed daily. Behavioral procedures were conducted between the hours of 9:00 AM and 2:00 PM. All animal testing was conducted in accordance with the National Institutes of Health guidelines for the Care and Use of Laboratory Animals and with an approved protocol from Temple University Institutional Animal Care and Use Committee.

\section{Drugs}

Cocaine hydrochloride was generously supplied by the National Institute on Drug Abuse, dissolved in sterile saline $(0.9 \% \mathrm{NaCl})$, and injected intraperitoneally (i.p.) in a volume 
of $3 \mathrm{ml} / \mathrm{kg}$ body weight. SB 216763 (Tocris; Ellisville, MO) was dissolved in $3 \% v / v$ DMSO, $3 \% v / v$ Tween 80 , and distilled water (3:3:94), and injected (i.p.) in a volume of $10 \mathrm{ml} / \mathrm{kg}$ body weight. Sterile saline or $3 \% \mathrm{DMSO} / 3 \%$ Tween $80 /$ distilled water were used for control vehicle injections.

\section{Cocaine conditioned place preference}

A randomized unbiased conditioned place preference procedure was used as described by us (Hummel et al. 2006) with some minor modifications. Conditioned place preference chambers were rectangular in shape $(45 \times 20 \times 20 \mathrm{~cm})$ and consisted of two compartments, separated by a removable door. One compartment had a smooth floor with white walls and vertical black stripes, while the other had a rough floor and black walls. On days $1-8$, mice were injected with saline or cocaine $(10 \mathrm{mg} / \mathrm{kg}$, i.p. $)$ and placed into alternate sides of the conditioning chamber for $30 \mathrm{~min}$. This was repeated once daily for 8 days with mice receiving four pairings with saline and four pairings with cocaine on alternate sides of the conditioning chamber. On test day (day 9), mice were given access to both sides of the conditioning chamber for $30 \mathrm{~min}$ in a drug-free state, and time in each side was recorded. Preference scores were determined by subtracting the amount of time spent in the saline-paired compartment from the cocaine-paired compartment.

\section{Protein measurements by immunoblotting}

Brain tissues of interest from individual mice were sonicated in $100{ }^{\circ} \mathrm{C} 1 \%$ sodium dodecyl sulfate with $1 \mathrm{mM} \mathrm{NaF}$ and $1 \mathrm{mM} \mathrm{Na} 3 \mathrm{VO} 4$ as phosphatase inhibitors. Samples were boiled for $5 \mathrm{~min}$, aliquotted, and stored at $-80{ }^{\circ} \mathrm{C}$. Protein concentrations of tissue samples were determined using a modified Lowry protocol (Lowry et al. 1951). Protein extracts $(25-40 \mu \mathrm{g})$ were separated on $7.5 \%$ Tris- $\mathrm{HCl}$ Bio-Rad Ready-gels (Bio-Rad Laboratories, Hercules, CA, USA) and transferred onto PVDF membranes. Membranes were subsequently blocked for $1 \mathrm{~h}$ in Odyssey blocking buffer and Tween-TBS and then incubated overnight at $4{ }^{\circ} \mathrm{C}$ in the following antibodies; phospho-Akt (Thr 308) $(1: 1,000$, Cell Signaling, Beverly, MA), phospho-GSK $3 \alpha / \beta(1: 1,000$, Cell Signaling, Beverly, MA), phospho-mTORC1 $(1: 1,000$, Cell Signaling, Beverly, MA), phospho- $\beta$-catenin $(1: 1,000$, Cell Signaling, Beverly, MA), Akt (1:2,000; Cell Signaling, Beverly, MA), GSK $3 \alpha / \beta$ (1:10,000; Santa Cruz, Santa Cruz, CA), mTORC1 (1:1,000, Cell Signaling, Beverly, MA), phosphoP70S6K (1:6,000, Cell Signaling, Beverly, MA), or $\beta$-catenin (1:1,000, Cell Signaling, Beverly, MA). Following overnight incubation in primary antibodies, membranes were washed in TTBS and incubated with anti-rabbit or anti-mouse secondary antibodies conjugated to two different infra-red dyes (LI-COR Biosciences, Lincoln, NE, USA) at $25^{\circ} \mathrm{C}$ for $1 \mathrm{~h}$ in the dark.
Secondary antibodies were diluted 1:20,000 in Odyssey blocking buffer with $0.1 \%$ Tween-20 (LI-COR). Membranes were visualized, and proteins were quantified using the Odyssey infrared imaging system and software. Phosphorylated and total forms of the kinases were detected simultaneously as the colors green and red, respectively. Membranes were stripped of antibodies using the New Blot nitro stripping buffer (LI-COR) and re-probed with anti- $\beta$-tubulin (1: 400,000; Sigma-Aldrich, St. Louis, MO) to control for potential differences in protein loading and transfer. Ratios of densities of phosphorylated proteins to $\beta$-tubulin levels, and total specific proteins to $\beta$-tubulin were calculated.

\section{Contextual fear conditioning}

Training and testing of contextual fear conditioning took place in four identical conditioning chambers $(17.78 \times 19.05 \times$ $38.10 \mathrm{~cm}$ ) housed in sound attenuating boxes (MED Associates, St Albans, VT), as described in Gould and Higgins (Gould and Higgins 2003). The front, back, and top of the chambers were constructed from Plexiglas panels, and the side walls were composed of stainless steel. The chamber floors, 18 metal rods spaced $0.6 \mathrm{~cm}$ apart, were connected to a shock generator and scrambler, and illumination was provided by a $28 \mathrm{~V}$ bulb located at the top of the left wall. Ventilation fans (69 dB), providing background noise and air exchange, were located on the right wall of each sound attenuating box. Stimulus administration was controlled by MED-PC software.

The fear conditioning procedure was performed as described previously (Davis et al. 2006). After habituating for $1 \mathrm{~h}$, animals were trained in foreground contextual conditioning.

Training began with a 148 -s period (Baseline) that was followed by a 2-s unconditioned stimulus (US) $(0.62 \mathrm{~mA}$ footshock). Following the first US was another 148-s period that was again followed by a 2-s US (0.62 mA footshock). Thirty seconds following the 2-s US, mice were removed from the training chambers and returned to their home cage. The overall training procedure lasted $5.5 \mathrm{~min}$. The first contextual testing day occurred $24 \mathrm{~h}$ after training. Mice were returned to the original training chambers (Context) for $5 \mathrm{~min}$, and freezing behavior was scored. SB 216763 (2.5 or $5 \mathrm{mg} / \mathrm{kg}$, i.p.) or vehicle was administered immediately after contextual testing, and mice were returned to their home cages. Twenty-four hours later, mice underwent a second contextual test wherein freezing was again scored for $5 \mathrm{~min}$ after mice were returned to the original training chambers (Context ReTest). Freezing, defined as the complete absence of movement besides respiration, was sampled for $1 \mathrm{~s}$ every $10 \mathrm{~s}$ during training and testing.

\section{Experimental design}

Experiment 1: The reactivation of cocaine-associated memory. In this experiment, two groups of mice ( $N=7 /$ group) 
underwent cocaine conditioned place preference as described above. Twenty-four hours following the test for cocaine place preference on day 9 , half of the mice were confined to the previous cocaine-paired compartment in a drug-free state for $10 \mathrm{~min}$ to reactivate their cocaine-associated memories $(\mathrm{Li}$ et al. 2010; Wu et al. 2011) and were euthanized immediately at the end of the cue exposure. The other half were kept in their home cage and served as a no-reactivation control at the same time. Mice were exposed to $\mathrm{CO}_{2}$ for $15 \mathrm{~s}$ and decapitated. The prefrontal cortex, nucleus accumbens, and caudate putamen were rapidly dissected on ice from a coronal brain slice, and the hippocampus was obtained by freehand dissection. Brain regions were prepared for measurements of phosphoproteins by immunoblotting as described above.

Experiment 2: Effect of the GSK3 inhibitor SB216763 on the reconsolidation of cocaine reward memory. Mice were randomly assigned to six groups $(N=7-8 /$ group). All groups of mice underwent cocaine conditioned place preference for 8 days as described previously and were tested for the expression of place preference on day 9 . On day 10 , four groups of mice were confined to the previous cocaine-paired context for $10 \mathrm{~min}$ to reactivate cocaine-associated memory, followed immediately by administration of either vehicle or $\mathrm{SB} 216763$ (1, 2.5, or $5 \mathrm{mg} / \mathrm{kg}$, i.p.). The other two groups of mice were injected with either vehicle or SB216763 $(2.5 \mathrm{mg} /$ $\mathrm{kg}$, i.p.) in their home cages according to the same time schedule but in the absence of cocaine memory reactivation. On days 11 and 18, all mice were re-tested for cocaineinduced place preference without further drug injections in order to determine if inhibition of SB216763 after memory reactivation could block cocaine place preference.

Experiment 3: The effect of SB216763 on the reconsolidation of contextual fear conditioning. The effect of SB216763 on the reconsolidation of fear-associated memories was investigated using contextual fear conditioning as described above, in order to test the specificity of the response to cocaine-associated memories. The study design paralleled the place conditioning procedure in that trained mice were re-exposed to the context, injected with SB216763 immediately following re-exposure, and tested $24 \mathrm{~h}$ later for responses to the context. More specifically, mice were trained on contextual fear conditioning procedures and tested for freezing to the context $24 \mathrm{~h}$ later. SB216763 (2.5 or $5 \mathrm{mg} / \mathrm{kg}$, i.p.) or vehicle was administered immediately following the test for contextual fear responses, and mice were returned to their home cages. Twenty-four hours later, a second contextual test was performed in the same environment.

\section{Data analysis}

Data were analyzed using a two-tailed Student $t$ test, one-way analysis of variance (ANOVA) or two-way ANOVA with exposure, and treatment factors followed by Bonferroni test for multiple comparisons (GraphPad Prism 4, La Jolla, CA), as required by study design. Grubb's tests were applied to the protein data in order to identify potential outliers, which resulted in the removal of 10 out of 334 data points.

\section{Results}

Phosphorylation of Akt-Thr308, GSK $3 \alpha$, GSK $3 \beta$, mTORC1, and P70S6K was downregulated in the nucleus accumbens and hippocampus following reactivation of cocaine-cue memories

Signaling pathways regulated by reactivation of cocainecontextual cue memories were identified in specific brain regions in experiment 1 . Mice underwent cocaine place preference conditioning for 8 days and were tested for preference on day 9. A significant preference for the cocaine-paired compartment was found (saline- vs. cocaine-paired compartment, $687.3 \pm 36.1$ vs. $1112.7 \pm$ $36.1 \mathrm{~s} ; t(28)=8.34 ; p<0.001)$. On day 10 , mice were re-exposed to the context previously paired with cocaine for $10 \mathrm{~min}$ or kept in their home cage and brains obtained immediately thereafter. Following re-exposure to the cocaine-paired environment, significant decreases in the phosphorylation of Akt-Thr308 $(t(11)=2.70$; $p<0.05), \operatorname{GSK} 3 \alpha(t(12)=2.50 ; p<0.05), \operatorname{GSK} 3 \beta(t(12)=$ $2.74 ; p<0.05), \operatorname{mTORC} 1(t(11)=2.74 ; p<0.05)$, and P70S6K $(t(11)=2.32 ; p<0.05)$ were found in the nucleus accumbens as compared with the levels in mice that underwent cocaine conditioned place preference but were not re-exposed to the cocaine-paired environment (Fig. 1a). Similarly, reduced levels of p-Akt-Thr308 $(t(11)=2.27$; $p<0.05), \quad \mathrm{p}-\mathrm{GSK} 3 \alpha(t(11)=2.35 ; p<0.05), \quad \mathrm{p}-\mathrm{GSK} 3 \beta$ $(t(10)=2.93 ; p<0.05), p-m$ TORC $1 \quad(t(12)=2.18$; $p<0.05)$, and $\mathrm{p}-\mathrm{P} 70 \mathrm{~S} 6 \mathrm{~K}(t(10)=2.65 ; p<0.05)$ were found in the hippocampus following cocaine memory reactivation (Fig. 1b). In the prefrontal cortex (Fig. 1c), exposure to the previous cocaine-conditioned environment lead to reductions in levels of p-Akt-Thr308 $(t(9)=2.58 ; p<0.05), p-G S K 3 \alpha \quad(t(11)=2.68 ; p<0.05)$, and p-GSK3 $\beta(t(8)=2.35 ; p<0.05)$ but not $\mathrm{p}$-mTORC1 $(t(12)=0.8 ; p>0.05)$ or $p$-P70S6K $(t(8)=1.61 ; p>0.05)$. Although trends towards reductions in p-Akt-Thr308, pGSK $3 \alpha, p-G S K 3 \beta$, and p-P70S6K were seen in the caudate putamen (Fig. 1d), these did not reach statistical significance (all $p$ 's $>0.05$ ). No significant differences were found in the levels of phosphorylated $\beta$-catenin in any of the brain regions (Fig. 1a-d). The levels of total Akt/tubulin, GSK $3 \alpha / \beta /$ tubulin, mTORC1/tubulin, P70S6K/tubulin, and $\beta$-catenin/tubulin did not differ between experimental groups in any brain region (data not shown). 
Inhibition of GSK3 disrupted the reconsolidation of cocaine reward memories

Since GSK3 was found to be activated by re-exposure to an environment previously associated with cocaine, the role of GSK3 in the reconsolidation of cocaine reward memories was investigated using the selective GSK3 inhibitor SB 216763. Following an 8-day cocaine conditioning paradigm, four groups of mice showed similar preferences for the cocainepaired compartment of the conditioning chamber on day 9 (Fig. 2a). On day 10, all groups of mice were confined to their cocaine-paired compartment in a drug-free state. After $10 \mathrm{~min}$ in the cocaine-paired environment, groups of mice were injected with either vehicle or $1,2.5$, or $5 \mathrm{mg} / \mathrm{kg}$ SB2 16763 and immediately returned to the home cage. Twenty-four hours later (day 11), preference was again tested. Two-way ANOVA of preference scores revealed significant main effects of SB 216763 dose $\left(\mathrm{F}_{3,76}=6.50, p<0.001\right)$ and test day $\left(\mathrm{F}_{2,76}=9.60\right.$, $p<0.001)$. Post hoc tests revealed that administration of SB $216763(2.5$ and $5 \mathrm{mg} / \mathrm{kg}$ ) immediately following reactivation of cocaine reward memories significantly attenuated preference for the cocaine-paired compartment when tested $24 \mathrm{~h}$ later $(p<0.01$ vs. vehicle day 11). Cocaine place preference was not significantly altered in mice injected with the lower dose of SB216763 $(1 \mathrm{mg} / \mathrm{kg})$ and was maintained in vehicle-injected mice at baseline levels (Fig. 2a, day 11). One week later, preference was retested, and again the vehicle-injected cohort maintained a significant cocaine place preference, whereas mice injected with SB216763 (2.5 and $5 \mathrm{mg} / \mathrm{kg}$ ) did not ( $p<$ 0.05 versus vehicle day 18 , Fig. $2 a$ ). These data indicate that SB216763 can disrupt cocaine reward memories.

Additional groups of mice underwent similar cocaine place conditioning and testing on day 9 (Fig. 2b). On day 10, these mice received the same treatments as the prior study (i.e., vehicle or SB216763 $2.5 \mathrm{mg} / \mathrm{kg}$ ), except the injections were given in the home cage without reexposure to the cocaine-paired environment. When preference was re-tested on day 11, both groups of mice successfully maintained their cocaine place preference (Fig. 2b). These data demonstrate that SB216763 was effective in blocking place preference only when administered after retrieval of cocaine-cue memories, suggesting that the drug is producing its effects specifically by interfering with reconsolidation of cocaine reward memory traces.

Inhibition of GSK3 failed to impair the reconsolidation of contextual fear memory

Contextual fear conditioning was used to determine the specificity of the effect of SB216763 on cocaine reward memories. The effects of GSK3 inhibition on reconsolidation of contextual fear memory was investigated by administering SB216763, 2.5, or $5 \mathrm{mg} / \mathrm{kg}$, or vehicle immediately after contextual testing in mice trained in the fear conditioning procedure; freezing to the context was re-tested $24 \mathrm{~h}$ after SB216763 administration. A two-way ANOVA revealed that SB216763 had no effect on reconsolidation as assessed by freezing during context re-test (no main effect of SB216763 dose, $\mathrm{F}_{2,96}=1.748, p=0.18$ ). Thus, SB216763 2.5 or $5 \mathrm{mg} / \mathrm{kg}$ administered immediately after contextual testing had no effect on the reconsolidation of fear memories (Fig. 3).

\section{Discussion}

The data presented herein demonstrate a critical role for the GSK3-mTOR signaling pathway in the reconsolidation of cocaine reward memories. GSK3 activity in the nucleus accumbens, hippocampus, and prefrontal cortex was augmented by reactivation of cocaine contextual memories. This was accompanied by reduced phosphorylation of mTORC1, a known target for inhibition by GSK3 (Inoki et al. 2006), and reduced phosphorylated P70S6K in the nucleus accumbens and hippocampus. Thr389-P70S6K is a direct phosphorylation site of mTOR and positively correlates with P70S6K kinase activity (Guertin and Sabatini 2007); phosphorylation of P70S6K is often used as a readout of mTOR activity (Hay and Sonenberg 2004). The importance of this pathway for the maintenance of cocaine-associated contextual memory is highlighted by the demonstration that inhibition of GSK3 with SB 216763 impaired the reconsolidation of cocaine associated memory, thus attenuating the expression of a previously established cocaine place preference $24 \mathrm{~h}$ and 7 days later. The ability of SB216763 to disrupt cocaine-associated memory only occurred when the drug was administered at the time of memory reactivation. When administered in the home cage environment, SB216763 had no effect on a previously established cocaine place preference. This provides further support that SB216763 interfered with the reconsolidation process rather than the expression of cocaine place preference.

The disruption of reconsolidation of cocaine reward memory was specific in our study, as the same doses of SB216763 (2.5 and $5 \mathrm{mg} / \mathrm{kg}$ ) administered immediately after recall of a contextual fear response, failed to impair reconsolidation of contextual fear conditioning, a task that is hippocampus-dependent. This finding suggests that either the association between the footshock and environmental cues is stronger than that for the cocaine-environment trace or that GSK3 activation is not necessary for reconsolidation of fear memories. A previous report demonstrates that heterozygote GSK3 $\beta$ null mice have impaired memory reconsolidation and that another GSK3 inhibitor AR-A014418 impairs contextual fear conditioning in wild-type mice when given 
a $\mathrm{NAC}$
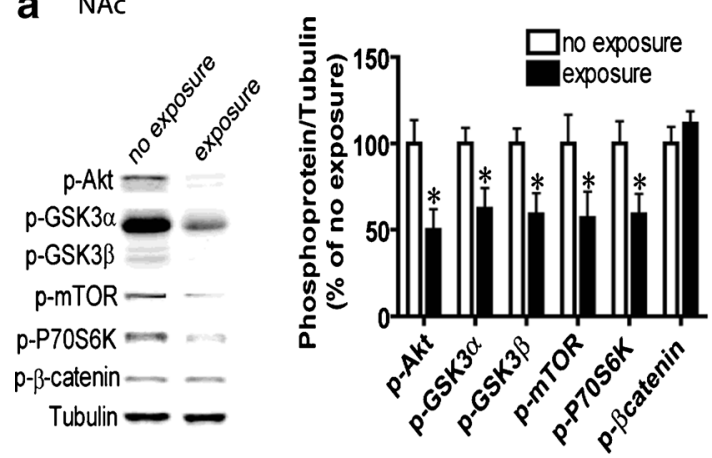

C $P F C$

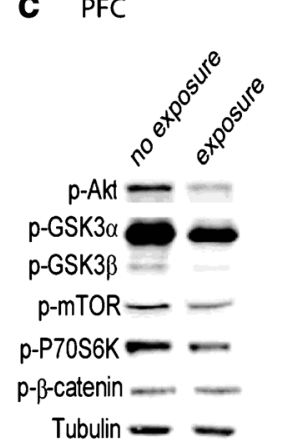

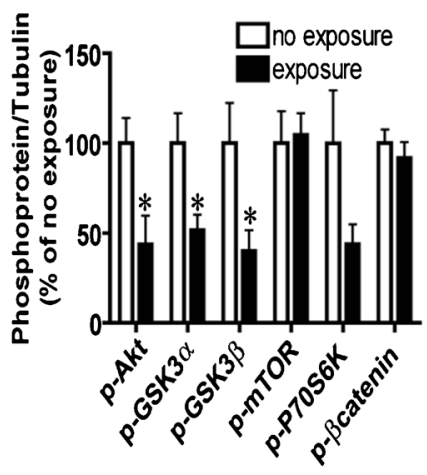

Fig. 1 Reactivation of cocaine contextual memory resulted in the dephosphorylation of Akt-Thr308, GSK3 $\alpha / \beta$, mTORC1, and P70S6K but not $\beta$-catenin in a brain region-specific manner. The phosphorylation states of Akt-Thr308, GSK $3 \alpha / \beta$, mTORC1, P70S6K, and $\beta$-catenin were measured in select brain regions following re-exposure of mice to the environment previously paired with cocaine, as compared with nonexposed controls. a Levels of p-Akt-Thr308, p-GSK3 $\alpha$, p-GSK3 $\beta$, pmTORC1, and p-P70S6K were significantly lower in the nucleus accumbens of exposed versus non-exposed mice ( $N=6-7 /$ group). Left, representative immunoblots of nucleus accumbens tissue from mice with or without exposure to the environment previously paired with cocaine. $\mathbf{b}$ Representative immunoblots of hippocampus tissue from mice with or without exposure to the environment previously paired with cocaine. Levels of p-Akt-Thr308, p-GSK3 $\alpha$, p-GSK $3 \beta$, p-mTORC1, and p$\mathrm{P} 70 \mathrm{~S} 6 \mathrm{~K}$ in the hippocampus were significantly lower in the mice re-

prior to memory reactivation (Kimura et al. 2008). The discrepancy between the results of Kimura et al. (2008) and the present study are likely due to the differences in the time of drug administration ( $1 \mathrm{~h}$ before contextual testing vs. immediately after the contextual testing). However, the different outcomes may also be due to differences in the mouse strains (C57BL/6 J vs. CD-1), age (7-10 months vs. 8 weeks), GSK3 inhibitors and/or doses (AR-A014418 vs. SB 216763), and/or procedures (three vs. two training trials).

Accumulating evidence suggests that NMDA receptors play a crucial role in cocaine-related memory reconsolidation (Alaghband and Marshall 2013; Bowers et al. 2007; Itzhak 2008), likely through their bidirectional effects on synaptic plasticity (long-term potentiation, LTP and long-term depression, LTD) (Sajikumar

\section{b Hippocampus}
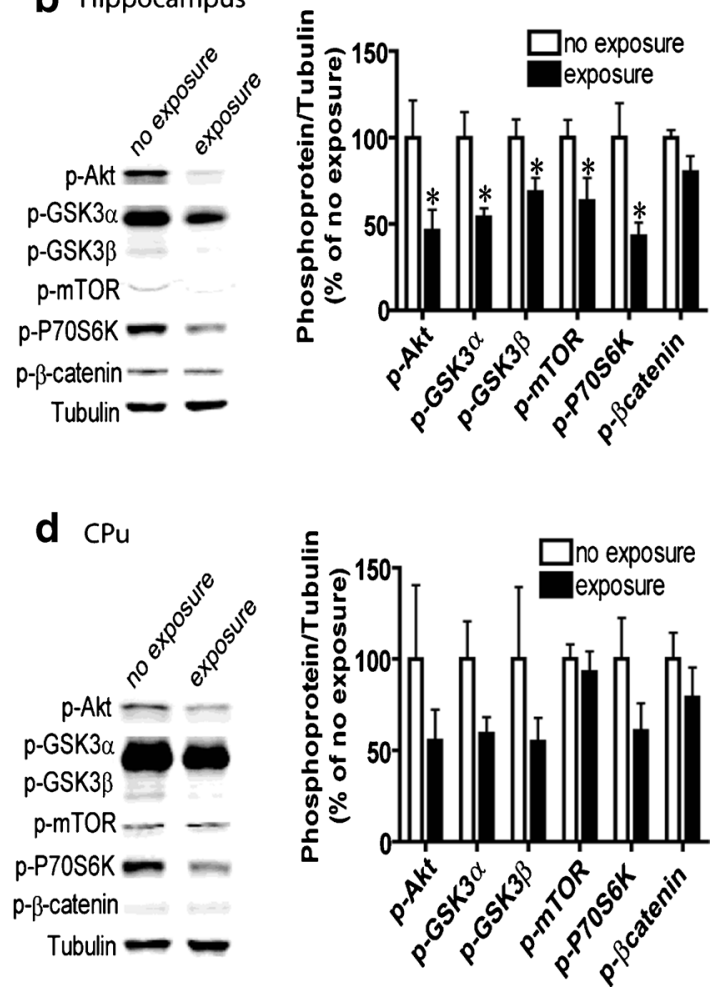

exposed to the cocaine context than in non-exposed controls $(N=6-7)$ group). c Representative immunoblots of prefrontal cortex tissue from mice exposed or not exposed to the environment previously paired with cocaine. Levels of p-Akt-Thr308, p-GSK $3 \alpha$, and p-GSK3 $\beta$ were significantly reduced following exposure to the cocaine context. No significant differences were found in levels of p-mTORC1, p-P70S6K, or p- $\beta$ catenin between the two groups ( $n=5-7 /$ group). $\mathbf{d}$ No significant differences were found in levels p-Akt-Thr308, p-GSK3 $\alpha$, p-GSK $3 \beta$, pmTORC1, p-P70S6K, or $\mathrm{p}-\beta$-catenin in the caudate putamen between exposed and non-exposed groups ( $n=5-7 /$ group). Bars represent the mean + SEM of phospho-protein/tubulin integrated density ratios expressed as percent of the ratio in the no exposure control groups. Data were analyzed by unpaired two-tailed $t$ test. ${ }^{*} p<0.05$, no exposure vs. exposure. $N A c$, nucleus accumbens; $P F C$, prefrontal cortex; $C P u$, caudate putamen

and Frey 2004). In memory reconsolidation, LTD maintains a prior potentiated circuit by competitive synaptic maintenance and protects stable memory traces (Diamond et al. 2005). Previous work has shown that GSK3 $\beta$ regulates the induction of hippocampal NMDA receptor-dependent LTD (Peineau et al. 2007a, b). Stimulation of NMDA receptors reduces Akt activity by decreasing Akt-Thr308 phosphorylation, while activating GSK3 $\beta$ through the dephosphorylation of the Ser9 residue (Peineau et al. 2009). The protein phosphatase 1 (PP1) inhibitor okadaic acid prevents the LTDassociated decreases in both phosphorylation of AktThr308 and GSK3 $\beta$. Therefore, during LTD, the activation of PP1 could activate GSK3 $\beta$ both by direct dephosphorylation and indirectly through inhibition of Akt (Peineau et al. 2007b). The data presented herein 
a
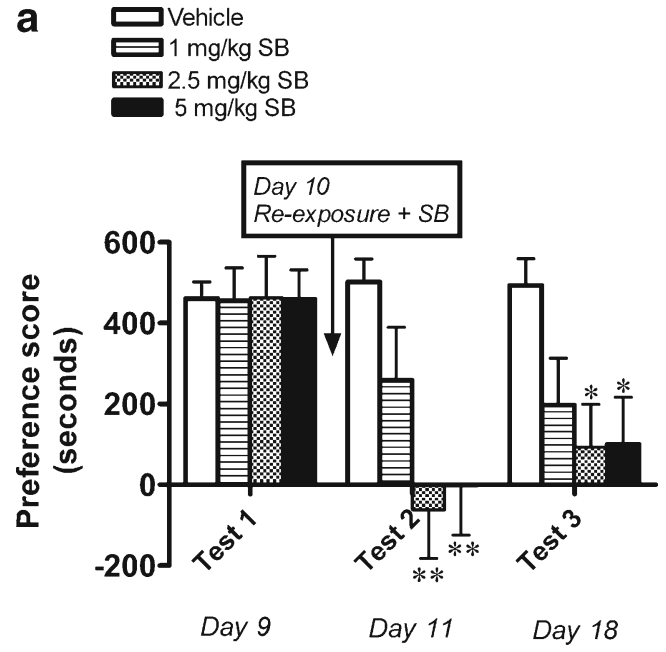

b
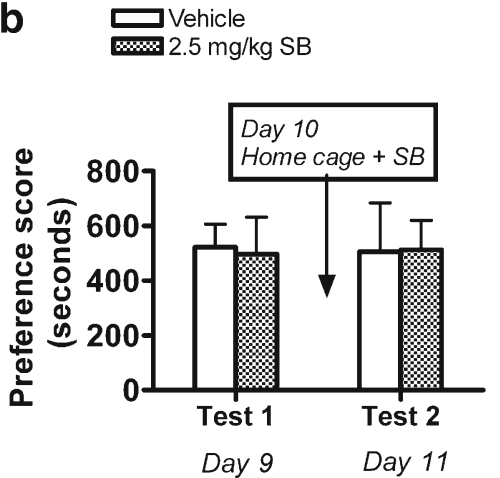

Fig. 2 Inhibition of GSK3 immediately following the reactivation of cocaine-associated memory impaired the reconsolidation of cocaineassociated memory. a Mice conditioned with cocaine (days 1-8) showed an initial preference toward their cocaine-paired environment (test 1, day 9). On day 10, mice were confined to the environment previously paired with cocaine for $10 \mathrm{~min}$, followed immediately by injection of SB216763 $(1,2.5$, or $5 \mathrm{mg} / \mathrm{kg}$, i.p.) or vehicle, and returned to the home cages. Place preference was retested $24 \mathrm{~h}$ later (test 2, day 11). Mice injected with 2.5 or $5 \mathrm{mg} / \mathrm{kg} \mathrm{SB} 216763$ showed no preference for the cocaine-paired environment when retested on day 11 (test 2) or again on day 18 (test 3 ). Data were analyzed by two-way ANOVA followed by Bonferroni test. $* p<0.05, * * p<0.01$ versus vehicle-injected group on the same test day ( $N=7-8$ /group). b Mice were similarly conditioned with cocaine as above and showed a significant place preference on day 9 (test 1). On day 10 , mice were injected with vehicle or SB216763 $2.5 \mathrm{mg} / \mathrm{kg}$ in the home cages. When retested for place preference on day 11, cocaine place preference was maintained. Data are expressed as means + SEM $(N=8$ / group)

demonstrate that the levels of phosphorylated Akt were reduced, as were phosphorylated GSK $3 \alpha / \beta$, in the hippocampus, nucleus accumbens, and prefrontal cortex of mice when cocaine contextual memories were reactivated. These results suggest that PI3K-Akt signaling is negatively regulated by the reactivation of cocaine-associated memory. Further experiments are needed to determine whether the dephosphorylation of Akt and GSK3 in our study is dependent on activation of phosphatases such as PP1.

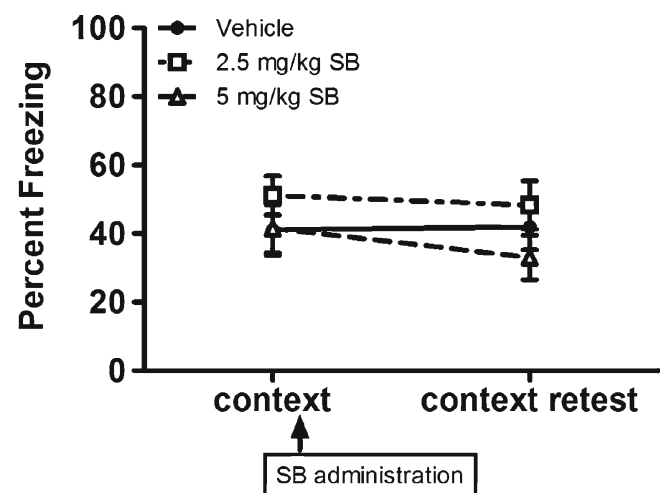

Fig. 3 Inhibition of GSK3 with SB216763 did not impair reconsolidation of fear memories. Mice underwent training for contextual fear conditioning. SB $216763,2.5$, or $5 \mathrm{mg} / \mathrm{kg}$, or vehicle was administered immediately after the test for contextual fear conditioning; re-testing occurred $24 \mathrm{~h}$ later. No difference in the amount of time spent freezing to the context between vehicle and SB 216763-injected groups was found. Data were analyzed by two-way ANOVA and are expressed as means + SEM of percent time spent freezing during the 5-min test session $(N=12$ / group)

In addition to Akt and GSK3, phosphorylation of mTORC1 was significantly downregulated in the hippocampus and nucleus accumbens following reactivation of cocaine-related memory. mTORC1 has been linked to memory formation and reconsolidation. For example, the mTORC1 inhibitor rapamycin injected into the nucleus accumbens core decreases cue-induced reinstatement of cocaine seeking (Wang et al. 2010). Likewise, rapamycin suppresses the expression but not the development of cocaine-induced place preference (Bailey et al. 2011). In addition, activation of mTORC1 is required for reconsolidation of fear memory, as rapamycin blocks the consolidation and reconsolidation of fear memory (Glover et al. 2010; Li et al. 2013; Parsons et al. 2006). However, this is the first report demonstrating that mTORC1 activity is reduced in the hippocampus and nucleus accumbens during reactivation of cocaine reward memories.

GSK3 $\beta$ together with $\beta$-catenin are components of the "destruction complex" which is regulated by canonical Wnt signaling (Logan and Nusse 2004). $\beta$-catenin is sequentially targeted for degradation by casein kinase $1 \alpha$ - and GSK $3 \beta$-mediated phosphorylation. Upon activation of Wnt receptors, the destruction complex dissociates, $\beta$-catenin accumulates, and then translocates into the nucleus where it promotes expression of Wnt response genes (Logan and Nusse 2004). As the Wnt/ $\beta$ catenin signaling pathway is involved in synaptic plasticity (Chen et al. 2006) and consolidation of fear memory (Maguschak and Ressler 2008) and is controlled by GSK $3 \beta$, its regulation was investigated in the present study. Re-exposure to the environment previously associated 


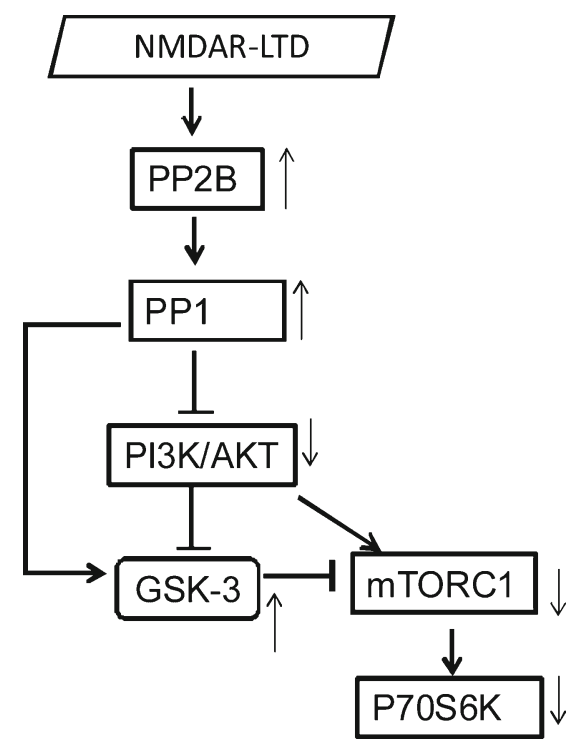

Fig. 4 Hypothesized model of molecular signaling underlying the reconsolidation of cocaine-related contextual memory. NMDA receptordependent LTD plays an important role in the reconsolidation of cocaineassociated memory. The results presented herein support a model by which a protein phosphatase cascade, such as PP2B and PP1, is activated during LTD and results in the dephosphorylation of Akt and GSK3 following the reactivation of cocaine contextual memories. The activation of GSK3 inhibits the activity of mTORC1. Arrows indicate the direction of regulation during reconsolidation. $G S K$, glycogen synthase kinase; mTORC1, mammalian target of rapamycin complex 1 ; $P I 3 K$, phosphatidylinositol 3-kinase; $P P 1$, protein phosphatase $1 ; P P 2 B$, protein phosphatase 2B

with cocaine reward was accompanied by activation of GSK $3 \beta$. Although GSK $3 \beta$ is able to phosphorylate $\beta$-catenin thus marking the protein for degradation, neither changes in the levels of phosphorylated nor total $\beta$-catenin was seen following re-exposure to the cocaine-paired environment. Therefore, the $\mathrm{Wnt} / \beta$-catenin signaling pathway might not be involved in the reactivation or reconsolidation of cocainerelated memory.

Previous work has indicated that the ERK signaling pathway is important for cocaine-associated contextual memory retrieval and/or reconsolidation. Inhibition of ERK activation at the time of re-exposure to an environment previously associated with cocaine attenuates a later preference for that environment (Miller and Marshall 2005; Valjent et al. 2006). It is currently unknown whether there is cross-talk between the ERK and GSK3 cascades in this regard or if they work independently to strengthen reconsolidation, perhaps in different brain areas. Further investigations are needed to resolve the relationship between these two signaling pathways in the context of cocaine reconsolidation.

Retrieval of cocaine cue memory engages a number of brain structures, including the prefrontal cortex, hippocampus, nucleus accumbens, basolateral amygdale, and ventral pallidum (Meyers et al. 2003; Soderman and Unterwald 2008; Weiss et al. 2000). In the present study, changes in Akt/GSK3/mTORC1 signaling pathway occurred in the hippocampus, nucleus accumbens, and prefrontal cortex following exposure to the cocainepaired environment, suggesting that these regions may play important roles in the process of drug-related memory retrieval and/or reconsolidation. Plasticity of cortical synaptic inputs to dorsal striatum (caudate putamen) is thought to play a role in striatum-dependent learning and memory (Gerdeman et al. 2003; Graybiel 1998), but this kind of learning and memory does not require protein synthesis-dependent reconsolidation upon retrieval (Hernandez and Kelley 2004). Hence, it was not unexpected that the caudate putamen did not show the same regulation of the $\mathrm{Akt} / \mathrm{GSK} 3 / \mathrm{mTORC} 1$ pathway after exposure to cocaine-paired contextual cues.

The findings presented herein are consistent with the following hypothesized model of the molecular mechanisms underlying the reconsolidation of cocaine-related contextual memory (Fig. 4). Recall of cocaine contextual memories causes the induction of LTD which involves a protein phosphatase cascade. $\mathrm{Ca}^{2+}$ entering the cell via NMDA receptors triggers the calcium/ calmodulin-sensitive enzyme calcineurin (PP2B). This dephosphorylates inhibitor-1, which leads to activation of PP1. PP1 is an activator of GSK3 $\beta$ via the dephosphorylation of GSK3 $\beta$-Ser9 (Peineau et al. 2007b). Thus, the dephosphorylation of Akt and GSK3 that occurred upon activation of cocaine-associated reward memory may be initiated by the activation of phosphatases such as PP1 during the induction of NMDA receptordependent LTD (reconsolidation of cocaine-related memory). The activation of mTORC1 and P70S6K is reduced accordingly as mTORC1 is a direct substrate of GSK3.

The results presented here demonstrate that Akt/GSK3/ mTORC1 signaling pathway in hippocampus, nucleus accumbens, and prefrontal cortex is engaged by reactivation of cocaine reward memories. Inhibition of GSK3 after reactivation of cocaine reward memories interferes with memory reconsolidation and prevents later cocaine-seeking activity. Thus, this pathway is critical for the reconsolidation of cocaine-associated contextual memories. Further study of these signaling pathways and circuitry may provide important insights into the development of effective therapeutics to prevent relapse to cocaine-seeking triggered by environmental cues.

Acknowledgments We would like to thank Mary McCafferty for her expertise in contributing to the successful completion of this study and Kevin Gormley and the NIDA drug supply program for generous contribution of cocaine to this study. This work was supported by the National Institutes of Health grants R01 DA09580 (EMU), P30 DA13429 (EMU), and T32 DA07237 (EMU/JSM). 
Funding R01 DA009580 [EMU], P30 DA013429 [EMU], and T32 DA007237 [EMU/JSM].

Competing interests The authors have no conflicts of interest to declare.

Open Access This article is distributed under the terms of the Creative Commons Attribution License which permits any use, distribution, and reproduction in any medium, provided the original author(s) and the source are credited.

\section{References}

Alaghband Y, Marshall JF (2013) Common influences of noncompetitive NMDA receptor antagonists on the consolidation and reconsolidation of cocaine-cue memory. Psychopharmacology (Berl) 226:707-719

Bailey J, Ma D, Szumlinski KK (2011) Rapamycin attenuates the expression of cocaine-induced place preference and behavioral sensitization. Addict Biol 17:248-258

Berke JD, Hyman SE (2000) Addiction, dopamine, and the molecular mechanisms of memory. Neuron 25:515-532

Bowers MS, Chen BT, Chou JK, Osborne MP, Gass JT, See RE, Bonci A, Janak PH, Olive MF (2007) Acamprosate attenuates cocaine- and cue-induced reinstatement of cocaine-seeking behavior in rats. Psychopharmacology (Berl) 195:397-406

Chen J, Park CS, Tang SJ (2006) Activity-dependent synaptic Wnt release regulates hippocampal long term potentiation. J Biol Chem 281:11910-11916

Cross DA, Alessi DR, Cohen P, Andjelkovich M, Hemmings BA (1995) Inhibition of glycogen synthase kinase-3 by insulin mediated by protein kinase B. Nature 378:785-789

Davis JA, Porter J, Gould TJ (2006) Nicotine enhances both foreground and background contextual fear conditioning. Neurosci Lett 394: 202-205

Diamond DM, Park CR, Campbell AM, Woodson JC (2005) Competitive interactions between endogenous LTD and LTP in the hippocampus underlie the storage of emotional memories and stress-induced amnesia. Hippocampus 15:1006-1025

Ehrman RN, Robbins SJ, Childress AR, O'Brien CP (1992) Conditioned responses to cocaine- related stimuli in cocaine abuse patients. Psychopharmacology (Berl) 107:523-529

Enman NM, Unterwald EM (2012) Inhibition of GSK3 attenuates amphetamine-induced hyperactivity and sensitization in the mouse. Behavioural Brain Research 231:217-225

Gerdeman GL, Partridge JG, Lupica CR, Lovinger DM (2003) It could be habit forming: drugs of abuse and striatal synaptic plasticity. Trends Neurosci 26:184-192

Gingras AC, Raught B, Sonenberg N (2001) Regulation of translation initiation by FRAP/mTOR. Genes Dev 15:807-826

Glover EM, Ressler KJ, Davis M (2010) Differing effects of systemically administered rapamycin on consolidation and reconsolidation of context vs. cued fear memories. Learn Mem 17:577-581

Gould TJ, Higgins JS (2003) Nicotine enhances contextual fear conditioning in C57BL/6 J mice at 1 and 7 days post-training. Neurobiol Learn Mem 80:147-157

Graybiel AM (1998) The basal ganglia and chunking of action repertoires. Neurobiol Learn Mem 70:119-136

Guertin DA, Sabatini DM (2007) Defining the role of mTOR in cancer. Cancer Cell 12:9-22

Hay N, Sonenberg N (2004) Upstream and downstream of mTOR. Genes Dev 18:1926-1945
Hernandez PJ, Kelley AE (2004) Long-term memory for instrumental responses does not undergo protein synthesis-dependent reconsolidation upon retrieval. Learn Mem 11:74854

Hummel M, Schroeder J, Liu-Chen LY, Cowan A, Unterwald EM (2006) An antisense oligodeoxynucleotide to the mu opioid receptor attenuates cocaine-induced behavioral sensitization and reward in mice. Neuroscience 142:481-491

Inoki K, Ouyang $\mathrm{H}$, Zhu T, Lindvall C, Wang Y, Zhang X, Yang Q, Bennett C, Harada Y, Stankunas K, Wang CY, He X, MacDougald OA, You M, Williams BO, Guan KL (2006) TSC2 integrates Wnt and energy signals via a coordinated phosphorylation by AMPK and GSK3 to regulate cell growth. Cell 126:955-968

Itzhak Y (2008) Role of the NMDA receptor and nitric oxide in memory reconsolidation of cocaine-induced conditioned place preference in mice. Ann N Y Acad Sci 1139:350-357

Jope RS, Roh MS (2006) Glycogen synthase kinase-3 (GSK3) in psychiatric diseases and therapeutic interventions. Curr Drug Targets 7: 1421-1434

Kimura T, Yamashita S, Nakao S, Park JM, Murayama M, Mizoroki T, Yoshiike Y, Sahara N, Takashima A (2008) GSK-3beta is required for memory reconsolidation in adult brain. PLoS One 3:e3540

Leroy K, Brion JP (1999) Developmental expression and localization of glycogen synthase kinase-3beta in rat brain. J Chem Neuroanat 16: 279-293

Li FQ, Xue YX, Wang JS, Fang Q, Li YQ, Zhu WL, He YY, Liu JF, Xue LF, Shaham Y, Lu L (2010) Basolateral amygdala cdk5 activity mediates consolidation and reconsolidation of memories for cocaine cues. J Neurosci 30:10351-10359

Li Y, Meloni EG, Carlezon WA Jr, Milad MR, Pitman RK, Nader K, Bolshakov VY (2013) Learning and reconsolidation implicate different synaptic mechanisms. Proc Natl Acad Sci U S A 110:47984803

Loewith R, Jacinto E, Wullschleger S, Lorberg A, Crespo JL, Bonenfant D, Oppliger W, Jenoe P, Hall MN (2002) Two TOR complexes, only one of which is rapamycin sensitive, have distinct roles in cell growth control. Mol Cell 10:457-468

Logan CY, Nusse R (2004) The Wnt signaling pathway in development and disease. Annu Rev Cell Dev Biol 20:781-810

Lowry OH, Rosebrough NJ, Farr AL, Randall RJ (1951) Protein measurement with the folin phenol reagent. J Biol Chem 193:265-275

Ma T, Tzavaras N, Tsokas P, Landau EM, Blitzer RD (2011) Synaptic stimulation of mTOR is mediated by Wnt signaling and regulation of glycogen synthetase kinase-3. J Neurosci 31:17537-17546

MacDonald BT, Tamai K, He X (2009) Wnt/beta-catenin signaling: components, mechanisms, and diseases. Dev Cell 17:9-26

Mactutus CF, Riccio DC, Ferek JM (1979) Retrograde amnesia for old (reactivated) memory: some anomalous characteristics. Science 204: $1319-1320$

Maguschak KA, Ressler KJ (2008) Beta-catenin is required for memory consolidation. Nat Neurosci 11:1319-1326

Meyers RA, Zavala AR, Neisewander JL (2003) Dorsal, but not ventral, hippocampal lesions disrupt cocaine place conditioning. Neuroreport 14:2127-2131

Miller CA, Marshall JF (2005) Molecular substrates for retrieval and reconsolidation of cocaine-associated contextual memory. Neuron 47:873-884

Miller JS, Tallarida RJ, Unterwald EM (2009) Cocaine-induced hyperactivity and sensitization are dependent on GSK3. Neuropharmacology 56:1116-1123

Nader K, Schafe GE, Le Doux JE (2000) Fear memories require protein synthesis in the amygdala for reconsolidation after retrieval. Nature 406:722-726

Parsons RG, Gafford GM, Helmstetter FJ (2006) Translational control via the mammalian target of rapamycin pathway is critical for the formation and stability of long-term fear memory in amygdala neurons. J Neurosci 26:12977-12983 
Peineau S, Bradley C, Taghibiglou C, Doherty A, Bortolotto ZA, Wang YT, Collingridge GL (2007a) The role of GSK-3 in synaptic plasticity. Br J Pharmacol 153(Suppl 1):S428-S437

Peineau S, Taghibiglou C, Bradley C, Wong TP, Liu L, Lu J, Lo E, Wu D, Saule E, Bouschet T, Matthews P, Isaac JT, Bortolotto ZA, Wang YT, Collingridge GL (2007b) LTP inhibits LTD in the hippocampus via regulation of GSK3beta. Neuron 53:703-717

Peineau S, Nicolas CS, Bortolotto ZA, Bhat RV, Ryves WJ, Harwood AJ, Dournaud P, Fitzjohn SM, Collingridge GL (2009) A systematic investigation of the protein kinases involved in NMDA receptordependent LTD: evidence for a role of GSK-3 but not other serine/ threonine kinases. Mol Brain 2:22

Proud CG (2007) Amino acids and mTOR signalling in anabolic function. Biochem Soc Trans 35:1187-1190

Przybyslawski J, Sara SJ (1997) Reconsolidation of memory after its reactivation. Behav Brain Res 84:241-246

Sajikumar S, Frey JU (2004) Late-associativity, synaptic tagging, and the role of dopamine during LTP and LTD. Neurobiol Learn Mem 82: $12-25$

Soderman AR, Unterwald EM (2008) Cocaine reward and hyperactivity in the rat: sites of mu opioid receptor modulation. Neuroscience 154 : $1506-1516$

Stoica L, Zhu PJ, Huang W, Zhou H, Kozma SC, Costa-Mattioli M (2011) Selective pharmacogenetic inhibition of mammalian target of rapamycin complex I (mTORC1) blocks long-term synaptic plasticity and memory storage. Proc Natl Acad Sci U S A 108: 3791-3796

Valjent E, Corbille AG, Bertran-Gonzalez J, Herve D, Girault JA (2006) Inhibition of ERK pathway or protein synthesis during reexposure to drugs of abuse erases previously learned place preference. Proc Natl Acad Sci U S A 103:2932-2937

Wang X, Luo YX, He YY, Li FQ, Shi HS, Xue LF, Xue YX, Lu L (2010) Nucleus accumbens core mammalian target of rapamycin signaling pathway is critical for cue-induced reinstatement of cocaine seeking in rats. J Neurosci 30:12632-12641

Weiss F, Maldonado-Vlaar CS, Parsons LH, Kerr TM, Smith DL, BenShahar O (2000) Control of cocaine-seeking behavior by drugassociated stimuli in rats: effects on recovery of extinguished operant-responding and extracellular dopamine levels in amygdala and nucleus accumbens. Proc Natl Acad Sci U S A 97:4321-4326

Woodgett JR (1990) Molecular cloning and expression of glycogen synthase kinase-3/factor A. EMBO J 9:2431-2438

Wu P, Xue YX, Ding ZB, Xue LF, Xu CM, Lu L (2011) Glycogen synthase kinase 3 beta in the basolateral amygdala is critical for the reconsolidation of cocaine reward memory. J Neurochem 118:113 125

Xu CM, Wang J, Wu P, Xue YX, Zhu WL, Li QQ, Zhai HF, Shi J, Lu L (2011) Glycogen synthase kinase 3beta in the nucleus accumbens core is critical for methamphetamine-induced behavioral sensitization. J Neurochem 118:126-139 